NBER WORKING PAPER SERIES

\title{
MONETARY POLICY IN AN UNCERTAIN ECONOMY
}

\author{
Martin Feldstein \\ Working Paper 9969 \\ http://www.nber.org/papers/w9969 \\ NATIONAL BUREAU OF ECONOMIC RESEARCH \\ 1050 Massachusetts Avenue \\ Cambridge, MA 02138 \\ September 2003
}

The views expressed herein are those of the authors and are not necessarily those of the National Bureau of Economic Research.

(C)2003 by Martin Feldstein. All rights reserved. Short sections of text, not to exceed two paragraphs, may be quoted without explicit permission provided that full credit, including (C) notice, is given to the source. 
Monetary Policy in an Uncertain Environment

Martin Feldstein

NBER Working Paper No. 9969

September 2003

JEL No. E5

\title{
$\underline{\text { ABSTRACT }}$
}

This paper discusses the nature of the uncertainty faced by central banks and considers three approaches to dealing with uncertainty(1) formal optimization models and robust rules based on such models; (2) informal rules like the Taylor rule and inflation targeting; and (3) a case by case approach based on an informal Bayesian logic. The latter case requires considering the asymmetric nature of the risks that the central bank often faces.

\author{
Martin Feldstein \\ National Bureau of Economic Research \\ 1050 Massachusetts Avenue \\ Cambridge, MA 02138-5398 \\ feldstein@nber.org
}




\title{
Monetary Policy in an Uncertain Environment
}

\author{
Martin Feldstein ${ }^{*}$
}

Monetary policy is inevitably made in an environment of substantial uncertainty. This has been particularly true in all of the major industrial countries in the past twelve months and continues to be so even now. Moreover, there has been an increased academic interest in formal ways for central banks to deal with uncertainty, with an increasing number of important papers. ${ }^{1}$

It is therefore good to take stock of these issues, not only to benefit policy officials but also to help economic researchers to focus their efforts. It is natural but inadequate to pose the central question of dealing with uncertainty as: How should central bankers deal with the uncertainties that they perceive? I say inadequate because there is a related problem for any central bank: recognizing that some of the facts and economic relations that it thinks it knows may actually be wrong. A correct perception of uncertainty requires increasing the subjective uncertainty of these variables and parameters and, more generally, to make monetary policy in a way that reflects the possibility that the "information" on which decisions are based is incorrect.

The problem is not just that the data that policy makers have is subject to revision, often to substantial revision. The history of monetary policy also contains a long list of fundamental but wrong views that were held with certainty by policy officials and widely accepted among academic specialists. Think, for example, of measuring monetary conditions by nominal interest

*Professor of Economics, Harvard University, and President of the National Bureau of Economic Research, Cambridge MA. These remarks were presented at the Jackson Hole Federal Reserve Conference organized by the Federal Reserve Bank of Kansas City, August 30, 2003 subject.

${ }^{1}$ See the paper by Carl Walsh (2003) for an excellent summary of recent papers on this 
rates, or judging the appropriate credit expansion by the real bills doctrine, or denying the ability of monetary policy to change inflation. Alan Meltzer's monumental new book (Meltzer, 2003) contains an impressive chronology of such false verities.

A list of just some of the uncertainties faced by the Federal Reserve today shows the kinds of uncertainties that are always present. Consider for example some of the uncertainties associated with the key variable, the rate of productivity growth. How fast is the productivity growth now and how fast will it be over the coming year? Will faster productivity growth lead to higher labor earnings and household spending or will it lead to reduced employment and higher unemployment? If actual aggregate demand grows more slowly than potential GDP, will inflation decline even if the economy is growing rapidly? If inflation declines to less than zero, will that start a destructive deflationary spiral or could deflation stabilize at a low negative rate? If faster productivity growth leads to increased unemployment, will the resulting increase in uncertainty among employed individuals cause them to increase their saving rate, thereby reducing the growth of aggregate demand? And how would household and business spending respond in this environment to a further decline in the Fed funds interest rate or other changes in monetary policy?

These current examples illustrate four kinds of uncertainty that frequently face every central bank: uncertainty about the current and future state of the economy; uncertainty about how the economy operates; the uncertainty of individuals about their personal futures; and uncertainty about the impact of potential future monetary policies. 
Before looking at the implications of these uncertainties for the conduct of monetary policy, it is important to emphasize that although this uncertainty affects the ability of a central bank to limit the variability of inflation and output, it does not limit the ability of central banks to avoid a high and rising level of inflation. There is no uncertainty about the key facts that can guide central banks to low long-term inflation: that even moderate inflation is harmful; that a high rate of inflation does not lead to a sustained low rate of unemployment or an increase in capital investment; and that monetary policy and real interest rates are the key ways to control inflation. So uncertainty is not an excuse for allowing inflation to go back to the bad old days. The effect of uncertainty on the behavior of households and firms has important implications for central banks. During boom years rising inflation in tight markets can cause an increase in expected future inflation that then leads to a spiral of rising inflation. A central bank that anchors expectations, i.e., that reduces uncertainty about future inflation, can more easily avoid such an inflation spiral.

In contrast, when the economy is weak and the central bank wants to increase demand, the uncertainty of households and firms depresses spending. By reducing uncertainty about future demand, the central bank can hope to stimulate spending. As recent experience shows, reducing uncertainty about future demand is much more difficult than providing a nominal anchor to limit future inflation.

This brings me now to the central question about how the Federal Reserve and other central banks can deal with uncertainty in setting monetary policy. I will divide my analysis into three parts: first, the role of formal models and model-based rules; second, informal target rules like the inflation targeting practiced by the Bank of England and the European Central Bank; and 
third, a case by case approach to making decisions under uncertainty.

There is now a large literature that uses explicit models of the economy to derive “optimal" policies, i.e., policies that minimize a weighted sum of the variances of inflation and real short-term growth of output while holding the mean inflation rate at some specified low level. A recent development of such modeling is the emphasis on finding a "robust rule" that has reasonably good performance under a variety of different plausible simple models of the economy even though the rule is not strictly optimal for any one of those models.

Such model-based exercises and robustness tests are useful for helping economists and some policy officials to think about these issues. But the models are far too limited for this to be an operational guide to policy. The models inevitably give inadequate attention to financial conditions, to changing institutions, to international markets, and to many other things. The criterion used to derive policy rules in the optimization models is also too limited, generally focusing on symmetric volatility in output and inflation rather than the risk of a deep recession or runaway inflation. Thus the models help to organize thinking but are not a substitute for judgement.

In practice, central banks use models to help organize conditional forecasts and sometimes as a starting point for decision-making. But no central bank uses such a formal model to derive its actual policies just as no company or bank uses a formal model to make its key management decisions. It is important that models continue to be developed and expanded to make them increasingly useful. But for the foreseeable future they will be an aid to judgement rather than a substitute for judgement. 
This brings me to the less elaborate rules or target procedures that have been adopted by many central banks and to inflation targeting in particular. An inflation target commits the central bank to aim at a particular inflation rate or range, typically to be achieved over a relatively short multi-year horizon and with the understanding that the central bank may choose to miss the target if unusual conditions make that appropriate.

Such a numerical target is attractive for anchoring inflation expectations, with potentially favorable effects on the economy and on financial markets. But all good things come at some cost. The potential gains from anchoring inflation expectations are no exception.

For example, an inflation target might actually weaken the credibility of a central bank if the central bank cannot or does not achieve the target value or range, especially if this failure to deliver persists for several years. Alternatively, a central bank might actually set its policy at some point in time to achieve the target inflation rate in order to reinforce its credibility even though doing so entails other outcomes, or risks, that it would otherwise want to avoid.

The decision of whether to adopt a numerical inflation target policy requires balancing these advantages and disadvantages. Recent research by Laurence Ball (2003) shows that the greater progress in reducing inflation in countries with inflation target rules reflects the higher rates of inflation that prevailed when targeting was introduced rather than any particular effectiveness of targeting per se.

Of course, a government or body politic that does not trust its central bankers to avoid increasing inflation might always want to impose such a rule to hold the central bankers accountable and to prevent their temptation to use unexpected monetary easing and inflation for a temporary economic stimulus. But if we take a more benign and principled view of central 
bankers $^{1}$, the desirability of adopting an explicit numerical inflation target depends on the need to do so in order to achieve inflation credibility.

I believe that the Federal Reserve has now earned that credibility by its record over the past twenty years, i.e., by delivering on its repeated statement of the goal of price stability. That credibility is reflected in the low inflation forecasts that are implicit in the yield differences between ordinary Treasury bonds and the inflation-protected Treasury bonds at every maturity. In contrast, for a new central bank like the European Central Bank or a central bank that has recently allowed very high rates of inflation, the advantage of an explicit inflation target may outweigh the disadvantages.

This implies that the decision to have or not to have an inflation target should not be regarded as a permanent decision. There are conditions that would justify or require a change with respect to numerical targeting, either adopting or exiting from such a policy.

This brings me to the operational issue of how to deal with uncertainty on a case by case, instance by instance, basis. The Federal Reserve does not need a rule like the Taylor rule or some more robust rule to be applied mechanistically in all circumstances. Indeed, as I have argued, trying to replace judgement with such a rule would generally be counterproductive.

The Fed only has to decide at each FOMC meeting what it will do then to the current interest rate and what it will say to the public about its actions and its intentions. That requires an implicit Bayesian decision analysis of the risks associated with different decisions, recognizing

${ }^{1}$ The paper by Kenneth Rogoff (2003) shows how inflation rates have declined in virtually every country around the world over the past few decades, including those with and those without explicit inflation targeting policies. It does not appear to be necessary to tie the hands of central bankers with an explicit rule or numerical target in order to achieve low inflation. 
that the outcome of different policies depends on the unknown state of the economy and the nature of the economy's reaction to policy changes. That approach is what Chairman Greenspan called a "risk management" approach to monetary policy (Greenspan, 2003). Although it is Bayesian in spirit, it avoids the technical difficulty of putting probability distributions on the parameters of a formal model or collection of formal models. Trying to do that strikes me as an essentially impossible task because the models are all "false models" that do not correspond to the actual economy. How can an economist put a subjective probability distribution on the parameters of a model when the economist believes that the model itself is false?

Of course, in making specific decisions, the Fed or other central bank has to consider not only the possible short-run effects of its action and statement but also the effect of its choice and its statement on the public's expectations of future monetary policy and therefore of future inflation.

How should uncertainty be taken into account in making this policy choice? The socalled "certainty equivalence" principle that uncertainty should be ignored and only the mean of each variable or parameter be used is essentially wrong. It is valid only under very restrictive conditions that are not applicable in practice. More general models can imply either smaller or larger changes in the interest rate because of uncertainty, depending on the structure of the model and on the nature of the uncertainty (see Walsh, 2003). So there is not much practical help here.

A paper by Milton Friedman, published more than 50 years ago (Friedman, 1951) offered an interesting insight on how policy should be influenced by uncertainty. Friedman noted that 
the level of aggregate demand at any point in time can usefully be regarded as the sum of the demand that would exist with no active policy plus the effect of current and past policy changes. The variance of aggregate demand is therefore the sum of the "no policy" variance and the "policy induced variance" plus twice the covariance between these two components. An active policy is therefore stabilizing (in the sense of reducing the variance of nominal demand) only if the covariance is negative and large enough to outweigh the increased variability introduced by the active policy.

This implies that the smaller the (absolute size of the ) negative correlation, that is, the poorer the ability of the Fed to time its policies in an offsetting way - the smaller should be the variability of the policy instrument. Friedman interpreted this as reason for a relatively inactive policy, and in the limiting case, for a constant growth rate of money. .

But Friedman's analysis, when applied on a case by case basis, suggests that the strength of the policy action should reflect the confidence with which the Fed believes that its action will be stabilizing and therefore the degree of uncertainty that it then faces. It also suggests that the appropriate action in the face of uncertainty depends on how difficult and how expensive it would be to reverse the policy or to correct an unwanted outcome after it occurs.

This implies that a strong expansionary monetary policy is more appropriate when the economy is far from full employment, when inflation is low, and when inflation expectations are desirable. In those conditions, the uncertainty about exactly where the economy is and exactly how strongly and quickly it would respond to lower interest rates is less important than it would be in an economy that was closer to full employment and that had a higher rate of inflation. This example also illustrates the importance of asymmetric risks. 
A prudent man (or, perhaps, I should say a prudent Bayesian) carries an umbrella even when the forecast says there is only a small chance of rain. If there is no rain, he suffers the small inconvenience of carrying the umbrella. But if he does not bring the umbrella and it does rain, he may suffer the much larger inconvenience of being caught in a downpour. The prudent central bank should behave similarly, accepting a high probability of a small adverse outcome in order to avoid the small risk of a very serious bad come.

Chairman Greenspan (2003) gave two examples of such behavior by the Fed: at the time of the Russian default and of the LTCM collapse. Monetary policy at the end of last year (lowering the federal rate from 1.75 percent to 1.25 percent) and the Administration's tax policy could both be characterized as prudent in the same sense because of the asymmetric nature of the risk faced at that time. Although a continued recovery seemed likely, it was far from a sure thing. Without further stimulus, the nascent upturn could lose steam, output could decline, and low inflation could become deflation. In short, a very bad outcome. In contrast, an unnecessarily strong monetary and fiscal stimulus could do little harm with the then current economic conditions.

The Fed pursued a prudent policy of lowering the Federal Funds raise from 1.75 to 1.25 percent and the Congress enacted a substantial tax stimulus. In retrospect, that was a risk worth taking. But even if it hadn't been needed, it would have been the prudent thing to do in the light of the uncertainty and the asymmetric risks at that time.

\section{Cambridge MA}

August 2003 


\section{$\underline{\text { References }}$}

Ball, Laurence and Niamh Sheridan, “Does Inflation Targeting Matter?” NBER Working Paper 9577,2003

Friedman, Milton, “The Effects of Full-Employment Policy on Economic Stability: A Formal Analysis," in M. Friedman Essays in Positive Economics (Chicago: The University of Chicago Press, 1953) and originally published as "Les effets d'une politique de plein emploi sur la stabilite economique: Analyse formelle," Economie Applique, IV (July-December 1951) pp 44156.

Greenspan, Alan “Opening Remarks," forthcoming in Monetary Policy and Uncertainty, the 2003 Kansas City Federal Reserve Bank conference.

Meltzer, Alan, A History of the Federal Reserve: Volume 1: 1913-51 (Chicago: The University of Chicago Press, 2003)

Rogoff, Kenneth, "Globalization and Global Disinflation," forthcoming in Monetary Policy and Uncertainty, the 2003 Kansas City Federal Reserve Conference.

Walsh, Carl, "Implications of Changing Economic Structure for the Strategy of Monetary Policy," forthcoming in Monetary Policy and Uncertainty, the 2003 Kansas City Federal Reserve Conference. 
